\title{
The emergence of signs of living feeling: Reverberations from the first Gatherings in Biosemiotics
}

\author{
Claus Emmeche ${ }^{1}$
}

What is biosemiotics and why bother - or gather - around it? During the final decade of the twentieth century, biosemiotics grew from being an idea conceived by a few semioticeans, biologists, ethologists and other specialists to becoming a more widely recognized perspective for the study of the "signs of life" as well as the "life of signs". Due to its unifying vision biosemiotics has implications, not only for a diversity of separate fields inside physics, biology, medicine, psychology, anthropology, semiotics, and philosophy as well as cross-disciplinary research programs such as cognitive science, artificial life or autonomous agents, but also for our very idea of living nature. Biosemiotic analysis may also offer interesting new ways of evaluating biological technology, and may also be seen as a fundamental new approach to theoretical biology. Biosemiotics has been on the agenda of many international meetings, and the 1990s saw a couple of publications devoted to biosemiotics proper (e.g. Sign Systems Studies vols. 27 and 28; Semiotica vols. $120(3 / 4)$ and $127(1 / 4)$, etc.).

As stated on a website recently established for this activity, ${ }^{2}$ Gatherings in Biosemiotics is intended to enact a regular framework for discussions of this new perspective on living beings. The gatherings will be international annual meetings for scholarly exchange of ideas and views in semiotic biology. Until this year's Gatherings, biosemiotics has not been the prime focus for any regular international activity, but hitchhiked on other initiatives. That has been a fruitful way of establishing such a new field of research, but time was ripe for a more focused platform for the discussion of biosemiotics as a biologically grounded domain of study and its relation to other fields of knowledge. For the present, Denmark and Estonia will alternate as hosts for these

${ }^{1}$ Author's address: Niels Bohr Institute, University of Copenhagen, Blegdamsvej 17, DK-2100 Copenhagen Æ, Denmark; email: emmeche@nbi.dk.

${ }^{2}$ See http://www.zbi.ee/ uexkull/biosemiotics/. 
meetings, and the first Gatherings took place in Copenhagen in May 24-27, 2001.

As a participant and co-organizer - together with Jesper Hoffmeyer and Kalevi Kull - I'll try to convey some personal impressions from the event, which took place in the building of Botanical Institute of the University of Copenhagen, the place where Wilhelm L. Johanssen in 1909 coined the terms 'gene', 'genotype' and 'phenotype' without intending all the materialist connotations that the notion of genes took on, especially after the breakthrough of molecular biology. It came as a nice surprise to the organizers that so many people reacted positively on our call for papers, and we ended up having 29 highly interesting papers presented by specialists from all over the world, during two and a half intense days. On the web site mentioned one can find a list of abstracts, and I do not intend to give a detailed summary of the whole programme here.

No wonder that whenever a new interdisciplinary field of research is on its way of establishing itself, questions pop up as to the scientific status of that field, its methods, and its relations to other areas of inquiry. We have seen that for general semiotics too. The very metaphor of a field may indeed be misleading, as one of the ambitions of biosemiotics is not so much to cultivate a special crop of scientific objects of investigation (like ichthyology, the study of fishes) as it is to connect patterns of knowledge from disparate sources of experience, and to contribute with one of the much needed supplements to the traditional experimental research. And of course, also to contribute to solve long standing puzzles and even deep metaphysical riddles left untouched by scientific progress. In his introduction to the prehistory of biosemiotics, Kalevi Kull from the University of Tartu, Estonia, emphasized that although biology is much too large to be comprehended neither by any biologist nor by semiotics or any other single approach, the semiotic perspective - a view that connects mind and matter - is so basic in understanding even the most simple living systems (cf. Thomas A.Sebeok's work on the modelling systems and the first cell as the starting point of semiotic processes), that the semiotic approach is necessary for all major branches of biology.

The meeting succeeded in establishing contacts between scholars who hitherto have been working independently and partly in parallel within that periphery of contemporary molecular and cell biology called theoretical biology. The cell biologist and expert on mitochondria Anton Markoš from Charles University in Czechia presented "a hermeneutics of the living", and gave an entertaining critique of the logocentric philosophy of life that has dominated western science, from St. John's Gospel, "in the beginning was the word" to the Central Dogma of molecular biology. But how to derive Marilyn Monroe from DNA and protein folding? Markoš pointed to ontogeny as the most crucial and often neglected problem in biology today and stressed that we may only understand a complex and developmental system in analogy with another complex system. Thus, doing biosemiotics proper - dealing with nature's own sign processes on various levels of organization - we are 
also forced to consider what may be called the system-observer semiotics, i.e., to inquire into the nature of the modelling relation of the various systems we can observe, describe, conceptualize and construct theories about, a semiotic of scientific experiment, observation, interpretation, operation and measurement. In this respect we have to consider critically our choice of ways of representing various sign system functions. In an ideally clear talk Yagmur Denizhan and Vefa Karatay from Bogazici University in Turkey presented a framework called "Evolution of the window", which allows one to describe how, during the course of evolution, complexity increases by meta-system transitions. There is a trend towards increasing semiotic interactions and the "evolvable window" stands for the totality of the semiotic interactions of an organism, including the models and meta-models used for anticipation. Their paper provided a promising way to synthesize the Peircean theory of sign interpretation with a complex systems perspective on multi-level integrative systems by using the notions of emergence and downward causation to describe how strong semiotic controls are generated with the appearance of, for instance, multi-cellular organisms.

Coming from social studies of science, Thierry Bardini from the University of Montreal, Canada, placed one of the central metaphors in molecular biology (and biosemiotics as well), that of the genetic code, in the perplexing but highly relevant context of metaphor theory in Paul Ricoeur, literary criticism, cognitive semantics and history of science (including Lily Kay's recent historical work on the genetic code). He used the discovery of "junk DNA" in gene mapping as a case to reflect upon the long running debate on the use of models and metaphors in science. Here, Jan T. Kim, a German bioinformatics scientist from the University of Lübeck, reacted by questioning the relevance of taking the metaphorics surrounding the human genome project in mass media's pop science at face value, when workers within the field are acutely aware of the fact that many of these notions are convenient ways of talking rather than scientifically adequate propositions. The form of this "convenience", however, needs further study, and so does the kind of (cryptosemiotic) knowledge that molecular biologists actually have about genes, DNA and codes. Later on, in a general discussion session, bravely moderated by anthropologist Myrdene Anderson from Purdue University in the USA, the hot topic about metaphors came up again, and she elegantly cached the saying "just a metaphor" and fixed it on the blackboard to further semiotic scrutiny. Evidently, various intuitions about the status of metaphors exist in the humanities and the natural sciences.

Several times during the gatherings questions were raised about the complex relation between human language and how we as humans "read" nature, including other semiotic agents in nature. The linguist Han-liang Chang from the National Taiwan University described some peculiarities of classical Chinese pictographic writing, especially how animals are named by citing all the creatures, real or fabulous, with a $/ \mathrm{ma} /($ horse) radical. In the discussion he questioned the universal validity of an analogy (based upon the analog/digital 


\section{Claus Emmeche}

distinction) in some early biosemiotic writings between written language (based on a digital alphabet) and life (based on the digital "DNA alphabet"): If one had taken departure in a "Chinese" understanding of written language, one might have sought for a metaphor that did not put the same weight on the genetic sequence, but focused on a structure or process that was already to some degree significant or minimally meaningful (as an icon is). The anthropologist-biologist Andreas Roepstorff from the University of Aarhus in Denmark analysed ethnographic material from Greenland to demonstrate that people there regard animals as "non-human persons", that is, as sensing and thinking beings who are able to build up knowledge about their environment. E.g., the behaviour of seals near icebergs are interpreted by human hunters who acknowledge semiotic competence to the seals regarding the state of the fragile and dangerous icebergs. Here, Lévi-Strauss' notion of "thinking with animals" in The Savage Mind takes on a new meaning, the animals are not simply embodiments of ideas already in the "savage mind"(or the world); rather, in this field of Greenlandic "experiential biology" (see below), animals are "persons", or biosemiotic agents, with both soul ['tarneq'] and body ['timi']. Both talks emphasized the limitations of a traditional western dualist account. Another participant, the ethologist Dominique Lestel from Ecole Normale Supérieure in Paris, gave a new interpretation of the human-animal interaction in the attempts to learn chimpanzees some kind of sign language. These experiments on talking apes were seen by Lestel not so much as experiments in psycholinguistics (how far can animal learn human language) but as wonderful experiments on the communities of communication between human beings and animals. He emphasized the necessity of strong emotional involvement of the human part of the relation, and suggested that human language should not be seen as a property that puts human being apart of other living creatures, but as something that makes human being able to better communicate with non human living creatures and to create hybrid communities of sharing interests, meaning and emotions.

It has long been evident that the semiotics of C. S. Peirce is a good starting point to develop a dynamic theoretical framework within biosemiotics, and a whole session were assigned to the Peircean approach. The Brazilian scholar Jorge de Barros Pires from Universidade Estadual Paulista, São Paulo, stressed the formal, general and normative aspects of Peirce's semiotics, as well as its definitely non-cartesian notion of a subject (or an agent, to use a more general term) - themes that are familiar to readers of this journal, but which is often difficult for biologists to understand when confronted with biosemiotics for the first time, e.g., that "an interpretant" is itself a sign that in no way needs necessarily to be an interpreter organism. The philosopher Tommi Vehkavaara from University of Tampere, Finland, suggested "to naturalize" semiotic concepts for biosemiotics. "Naturalising" mentalistic concepts has for long been a cottage industry in empiricist and analytic variants of philosophy of mind that try to accommodate the waves of reductionist research in "cognitive science". However, as far as I can see, Vehkavaara's 
suggestion to redefine semiotic concepts (agent, consciousness, pain, etc.) in terms of "concepts referring to external experiences" may well be hard to reconcile with the basic non-dualist ontological perspective in Peirce, and such a project's own metaphysical presuppositions need to be clarified, despite the possible gain in clarity and "objectivity" of such concepts as the very notion of a sign's object, a point Vehkavaara stressed. Another attempt to make Peircean notions of sign interpretation more palatable to scientists was Alexei Sharov's version of a "pragmatic approach" to biosemiotics. Sharov, formerly a Russian zoologist now at the Virginia Technical University in USA, is well-known within the emerging biosemiotic community. He has developed what I would call an operationalist version of biosemiotics in which signs are seen as generated and interpreted as agents who have goals and values, and as anticipatory systems these agents control their own probability of transition. Sharov showed how such an approach was accessible for mathematical treatment and could be applied to economic agents (concerned with "present value") as well as Darwinian agents (concerned with "reproductive value"). Such an approach may indeed be useful to bridge the gap of communication between contemporary evolutionary biology and biosemiotics. Though it may be in discord with the "internalist" critique of neoDarwinism deriving from some biosemiotic works, only time will show whether we shall get a semiotization of neo-Darwinism or an "economiczation" of biosemiotics!

The meeting showed that transdisciplinary synthesis can be configured in a variety of ways, extending the horizon of the founding figures of semiotics. Søren Brier, the editor of Cybernetics \& Human Knowing from the Royal Veterinary and Agricultural University in Copenhagen, presented his bold systemic "cybersemiotic" theory, drawing on figures such as Peirce, N. Luhman, Maturana and Varela, K. Lorenz, and even elements of Wittgenstein's philosophy of language, taken in and transformed into this synthetic endeavour. For the particular occasion, Brier presented a new concept, called "intrasemiotics", denoting the interpenetration of sign-games situated within biological, psychological and social systems, as illustrated in one of his complex diagrams that made one of the participants complain that such kind of Venn-like diagrams made him feel like looking at a map of the former Yugoslavia with all its territories, but are all these spheres and borders really pertaining to reality? An interesting discussion followed about whether we actually as human agents distinguish between our biosemiotic, psychosemiotic and sociosemiotic activities. Another synthetic theory, more formal in approach, was presented by Edwina Taborsky, a semiotician from Bishop's University in Canada, editor of the on-line journal of Semiotics, Evolution, Energy, Development. She outlined an ambitious attempt to describe the ontological and epistemological architecture of evolutionary semiosis, based on an extremely general (pansemiotic) notion of codification, i.e., "patterns of organization of energy", in which also "information" is codified energy. Having had difficulties earlier of precisely getting at the Taborskyan way to cut up 
the universe, I was delighted to see a much more clarified and, it seemed to me, consistent exposition of her version of a modernized Peircean metaphysics. The basic intent of her talk, if not her specific conceptual scheme, was later supported and made concrete by another pansemioticean, the physicist Peder Voetmann Christiansen from the University of Roskilde in Denmark. He interpreted Peirce's notion of habit formation as symmetry breaking in the early universe and gave a beautiful talk about the Peircean categories of Firstness, Secondness and Thirdness in relation to the cosmology of the early universe and physical concepts of "virtual fluctuations", "nucleation" (with its tendency to spread out and form larger islands of order) and irreversibility. Furthermore, he addressed the relation between bio- and physicosemiosis by noticing that "life" is not simply the particular set of objects investigated by biology; life as such is an internal quality of matter, called "living feeling" by Peirce, and in this sense, the biological organism is encoded life, similar to the phenomenon of matter as being encoded energy.

Another new term introduced at the meeting was Tom Ziemke's "robosemiotics". Ziemke, a researcher in autonomous robotic systems at the University of Skövde in Sweden, has embraced the "new robotics" movement that in many respects is much more biologically interesting than traditional AI-styled robotics. Still, these artificial "creatures" have an intrinsic semiotic activity that in many respects is organized quite differently from "real" autonomous organisms, as Ziemke convincingly showed, much inspired by the old biosemioticean Jakob von Uexküll's characterization of the sensing organism and its Umwelt (a coming issue of Semiotica will deal with J. von Uexküll). An interesting and newly discovered form of sensing, "quorum sensing" in bacteria, was explored by the Venezuelan researcher Luis Emilio Bruni, presently at the biosemiotics group at the University of Copenhagen. He exposed some of the molecular and ecological details of this fascinating system, consisting of a community of bacteria living in symbiosis inside a squid, who exploit the light-production of the bacteria to camouflage its shadowy gestalt when seen by predators from below against the moonlight.

Stepping up several levels of organization, there were papers dealing with the biosemiosis of the nervous system. In a thrilling talk the neurobiologist Donald Favareau from the University of California, Los Angeles, USA, discussed the neurosemiotic emergence of intersubjectivity and empathy. He saw biosemiotics as a way to ask the crucial questions that are often left behind in experimental research, and as a way to escape what he called "the fallacy fallacy" - i.e., smuggling down higher level varieties of semiosis to lower levels, claiming that only lower levels should be the "real" ones (e.g., that "racism" is something to be located exclusively in the brain). He balanced his view between Searle's observation that "I speak English, my neurons don't" and his own contribution to investigate the important role of so-called mirror neurons to code for highly specific kinds of actions. And from actions, we can have a self: A significant contribution of the mirror neuron system to human cognition is not the dualistic idea that representation is mutual between agents 
("my representation of $x$ and your representation of $x$ occur similarly in both of us, therefore you and I are similar") but, rather, the biosemiotic conceptual orientation that intersubjectivity - mutuality itself - is an intrinsic property of representational experience within agents ("my (primary level) representational experience of $x$ is mutual to both my (higher-order) representational experience of myself and to my (higher-order) representational experience of you"). Martin Skov, a scholar from the University of Copenhagen, focused on the lack of knowledge (in brain as well as sign science) of how the nervous system integrates various kinds of information and pointed to Terrence Deacon's work as a promising example of the development of "neurosemiotics". And Anton Fuerlinger, a member of the Konrad Lorenz Institute for Evolution and Cognition Research near Vienna, Austria, complemented by pointing to the centrality of the organism's movement for a natural history of the higher level "codes": As brains are really the organisms' movement detectors, and movement is closely coupled with measuring (and remembering and comparing) the muscles positions, neuroscience has to take seriously the semiotics of the coherent neuro-muscle system. After several attempts to present a power point presentation, but failing because of technical problems of compatibility (a challenge for another kind of semiotics) Jyoo-Hi Rhee, a philosopher from Bielefeld University, Germany, finally chose to embody her digitalized paper and thus gave an in-depth critique of some of the prevailing metaphysical presuppositions in philosophy of mind regarding the "hard" problem of qualia (such as Jaegwon Kim's presupposed requirement of "causal closure of the physical universe"). Instead, she proposed to see qualia as biologically generated signs, a kind of natural sign-processing, and to redefine "the physical" and "the mental" as special ways to represent the world.

Needless to say that these brief remarks cannot do justice neither to any of the presented papers, nor to their many interrelations. After the powerpoint breakdown, Stefan Artman, a philosopher from Friedrich Schiller University in Jena, Germany, who introduced himself as coming from the Gutenberg age as he would "read" his paper, presented a clear conceptual analysis, based on the Kolmogorov-Chaitin theory of algorithmic complexity, of three types of semiotic indeterminacy, and applied this to a critical elucidation of the famous essay Le hasard et la nécessité by the molecular biologist and Nobel price winner Jacques Monod. The author of this note, a theoretical biologist, talked about an internal relation between the notion of function in biology and the notion of sign action in biosemiotics, both implying the organism as an irreducible complex structure. The organism is, of course, a crucial biological concept, often left out of focus in experimental biology, as well as a phenomenon of everyday "experiential" biology, and its causal structure involves a form of "downward causation" similar to the Aristotelian categories of formal and final causes. Wolfgang Hofkirchner from Vienna University of Technology, Austria, presented his reflections about biosemiosis in the context of emergent levels of self-organization. Abir U. Igamberdiev, a Russian biologist from Voronezh University, now at the Risø Laboratory in Denmark, 


\section{Claus Emmeche}

gave a rich talk about the semiotic structure of living systems, addressing imprints, codes and language games. The linguist Tuomo Jämsä from the University of Joensuu, Finland, developed a sketch for a biosemiotic version of speech act theory. Andres Luure from Tallinn Pedagogical University in Estonia talked about functional, adaptational and symbolic semiosis by taking his point of departure in theory of reference within contemporary philosophy of language, and suggested that referential expressions refer to objects, not in the world but in some model that asserts the existence of, say, a man with a glass of Martini standing in the corner, notwithstanding that the same man, in a better model, is most shockingly drinking water!

The last session included a talk by a central figure of contemporary biosemiotics, Jesper Hoffmeyer from the University of Copenhagen. He addressed the presumable schism between the "pansemiotic" approach (such as that of Voetmann Chrisiansen and Taborsky) and his own biosemiotic one. The point was that there is no real schism; pansemiotics is an unlucky term insofar it connotes "imperialist" aims, but in some sense we cannot do without at least some degree of a very broad notion of sign action in all of nature to have a genuine natural history of "subjectness" on the cosmic scale. It is logically impossible merely by the mechanics of natural selection to generate sentient living beings if there were no precursors of life and "living feeling" in the pre-biotic universe. Here, Hoffmeyer acknowledged the central role of Voetmann Christiansen for introducing to Danish scientists the broad Peircean outlook, and in particular for his way to reconcile bio- and physicosemiotics.

The Bateson-specialist and anthropologist Peter Harries-Jones from York University in Toronto, Canada, commented upon Gregory Bateson's important legacy in biosemiotics and his pivotal role for establishing a theory of the social inter-subjective aspects of biosemiosis, seen, for instance, in such phenomena as play, social exchange and reciprocity. Thus, higher order units of interpretation have to be considered in addition to Peirce's triadic signs and Uexküll's Umwelten. Finally, the immunologist Elling Ulvestad from Haukeland University Hospital in Bergen, Norway, gave an entertaining talk about the research on extraterrestrial life in which he compared biosemiotics as a field to astrobiology: SETI (Search for Extraterrestrial Intelligence) is indeed dealing with semiotic problems in deciding how to go about to detect extraterrestrial intelligent life, and addressing problems like "how does life begin and evolve?", "is the genetic code universal?" etc. And as what one ought to know, some satellites have indeed detected evidential signs of life on Earth.

You do not remember everything you do the first time. But the First Gatherings concluded with a shared and pretty living feeling that a rich field of research, germinating in distant areas of the world, have now progressed to a state where its further maturing imply a continuing and critical interaction by a diverse community of inquirers; and I look forward to the coming gatherings with the innocent hope that they will be just as intellectually joyful as the first. 